\title{
CORRESPONDENCE
}

\section{Appropriate Hydration Can Make a Difference}

Shizma Junejo ${ }^{1 *}$, Talea Hoor ${ }^{1}$, Misbah Riaz ${ }^{2}$

ABSTRACT

Water is an essential component in terms of having a role in building of human body. The total body water content must be adequately maintained for the health and wellbeing of an individual. Water intake as well as water loss is governed by efficacious homeostatic mechanisms which are receptive to even minute changes such as hundred milliliters. Water deficit happens as hypohydration when fluid intake is not sufficient to replace fluid losses. When water loss exceeds the amount of water consumed, dehydration results. Mild dehydration is described as fluid loss being around 1-2\% of total body fluids. Severe dehydration occurs with fluid loses over $5 \%$. Dehydration has remarkable consequences including effect on body temperature, respiratory rate, mental functioning and muscle endurance. Overall, the role of water as a necessary nutrient is indispensable. Consequently, appropriate hydration status is extremely imperative for health and wellbeing of an individual.

The human body contains around $70 \%$ of water. ${ }^{1}$ In terms of body weight water makes up $75 \%$ in infants and $55 \%$ in elderly. ${ }^{2}$ Water is necessary for cellular homeostasis as well as life. ${ }^{2}$ Still plentiful unanswered questions exist regarding this extremely imperative constituent of our body and our diet. ${ }^{2}$ The water in the body has diverse physiological roles. ${ }^{1}$ These include being required for breathing for oxygen transport to the cells, metabolism, digestion and absorption of nutrients, detoxification of the body, regulation of body temperature, upkeep of equal osmotic pressure in cells as well as extracellular space etc. ${ }^{1}$ Water should be treated as vital nutrient in diet. Accordingly, it is imperative for health to have total body water (TBW) content in appropriate standards.

The indicator for water intake is primarily thirst. ${ }^{3}$ The thirst sensation is managed by the central nervous system that gets signals pertinent to hydration status from central as well as peripheral pathways. ${ }^{3}$ Identical to calories, the correct amount of water to be drunk is controlled by the balance between the intake as well as the losses. The intake is by means of fluids as well as solid foods. ${ }^{3}$ From food, fruits and vegetables are the leading source of water. Water emanating from oxidation of macronutrients makes a contribution as well, though usually inconsequential. $^{3}$

As an aftermath of thermoregulatory sweating body water is lost. Furthermore when fluid intake is not sufficient to reconstitute sweat losses a water deficit results as hypohydration. ${ }^{4}$ Amongst individuals indulging in exercise or being exposed to warm climates as a result of loss of sweat, acute mild as well as moderate hypohydration can be to some extent common. ${ }^{5}$ This may also happen in situations of diminished fluid intake or as a result of consumption of diuretics. ${ }^{5}$ The loss of body fluids outstripping the amount which is taken in, interrupting the delicate equilibrium of minerals in body fluids, culminates in dehydration. ${ }^{1}$ Mild dehydration results from body loses around $1-2 \%$ of total body fluids. Furthermore severe dehydration is investigated as taking place when body loses over $5 \%$ of the total fluids. ${ }^{1}$ Likewise a heat wave that took place in Paris, France in 2003 eventualized in a $2 \%$ elevation in mortality. ${ }^{6}$ Majority of deaths occurred in vulnerable groups and happened as a result of heat-related illnesses, such as dehydration. ${ }^{6}$ As advocated by the American College of Sports Medicine (ACSM) Guidelines on Exercise and Fluid Replacement and the position of the Academy of Nutrition and Dietetics on Nutrition and Athletic Performance, dehydrated individuals should have an intake of 1.25 to $1.50 \mathrm{~L}$ of fluid per kilogram of body mass (BM) lost to restore body water content, if the fluid deficit is huge and recovery time is restricted to around less than $12 \mathrm{~h}{ }^{7}$

Mild dehydration can happen during peculiar times in a day, due to poor hydration habits and restricted access to a variety of beverages or foods like in work environments. ${ }^{8}$ Overall severe dehydration curtails performance, results in difficulties in concentrating, headache, irritability, sleepiness and elevates body temperature and respiratory rate. An acute dehydration can develop in hours. ${ }^{9}$ The physiological causes for poor performance as a result of dehydration encompass thermoregulation, hyperthermia, cardiovascular strain, increased glycogen utilization as well as reduced skeletal muscle blood flow. ${ }^{10}$

Regarding hydration, it is acknowledged that dehydration as a result of loss of body weight over $2 \%$ of initial body weight has a negative effect on the exercise performance and undermines muscular endurance, mental 
functioning as well as thermal regulation. ${ }^{11}$ As exhibited by research most of the athletes have a tendency to count on a sense of thirst to apprise them regarding desire to drink fluids in the course of training sessions as well as competitions. ${ }^{12}$ Disastrously when athletes depend on a sense of thirst alone, they do not by choice drink sufficient fluid to avert the development of dehydration during exercise. ${ }^{12}$ On the whole, the research demonstrates that the sports performance of numerous athletes is possibly being thwarted by inadequate hydration habits. ${ }^{12}$

Hydration status can have an effect on the pharmacodynamic as well as pharmacokinetic properties of medication. ${ }^{7}$ A distorted hydration state, notably dehydration, has been revealed to have a brunt on kidney function. Additionally this can disturb the safety and efficacy of a few drugs, peculiarly those having a narrow therapeutic range, including lithium. ${ }^{7}$ It was documented in a study by Strippoli et al that inverse relationship exists between water intake as well as the risk of having chronic kidney disease, such that individuals having an intake of 3.2L of fluid a day having lower risk in contrast to those having consumed $1.8 \mathrm{~L}$ in a day. ${ }^{7}$

The brain's decision to commence or halt drinking as well as to select the suitable drink is done before the ingested fluid reaches the intra and extracellular compartments. ${ }^{2}$ Messages are sent from the taste buds in the mouth to the brain regarding the nature of the ingested fluid. The neuronal responses are elicited as though the coming in water had by that time reached the bloodstream. ${ }^{2}$ Drinks are also used up for their energy content including soft drinks and milk. Also in warm weather drinks are utilized for cooling and in cold weather for warming. Drinking like this is suggested as being moderated via the taste buds, that communicate with the brain in a rather reward system and their mechanisms are merely in initiation to be understood. This bias by means of which human beings rehydrate themselves can be beneficial as it permits water losses to be regained prior to occurrence of thirst-producing dehydration. ${ }^{2}$ Regrettably this bias is also coupled to adverse circumstances. In relation to beverages the dominant concerns are their energy content and their ramifications on dental health. ${ }^{13}$ Due to obesity levels perpetually surging, it is essential for greater part of population to control their energy intake and foods also must be given due consideration for their energy content. Concerning dental health there are two issues, dental caries as well as dental erosion. ${ }^{13}$ Water intake suggestions by Institute of Medicine (IOM) and European Food Safety Authority (EFSA) on the whole range from 2-2.7 L/day for adult females and 2.5-3.7 L/day for adult males. ${ }^{14}$ As with other essential substances, suggestions for water intake are provided by various authoritative bodies. ${ }^{14}$

Water balance is adjusted by delicate as well as meticulous homeostatic mechanisms that control water intake as well as losses. ${ }^{2}$ Insufficiency or overload of precisely a meager hundred milliliters activate these mechanisms and as small as losses of around $1 \%$ of body water will be amended in 24 hours. ${ }^{2}$ Our health can be put in jeopardy as a result of shortfalls in body water, if they culminate in sizable disruption in water balance. ${ }^{13}$ In order to accomplish needs, humans cannot acquire sufficient amount of required water by metabolism or get adequate water by means of food ingestion. ${ }^{15}$ Consequently, it is necessary to pay attention to what we drink in the entire day to make sure that we catch up with our daily water needs, as failure to do so can lead to negative health effects. Water is fundamental for life. ${ }^{15}$ Without water, humans can survive only for days. ${ }^{2}$

How to cite this: Junejo S, Hoor T, Riaz M. Appropriate Hydration Can Make a Difference. Life and Science. 2022; 3(1): 63-65. doi: http://doi.org/10.37185/LnS.1.1.214

This is an Open Access article distributed under the terms of the Creative Commons Attribution License (http://creativecommons.org/licenses/by/4.0), which permits unrestricted use, distribution, and reproduction in any medium, provided the original work is properly cited

${ }^{1}$ Department of Pharmacology/Biochemistry ${ }^{2}$

Bahria University Medical and Dental College, Karachi

Correspondence:

Dr. Shizma Junejo

Department of Pharmacology

Bahria University Medical and Dental College, Karachi

E-mail: shizjunejo@hotmail.com 
Funding Source: NIL; Conflict of Interest: NIL

Received: Jun 06, 2021; Revised: Sep 18, 2021

Accepted: Dec 09, 2021

\section{REFERENCES}

1. Krecar IM, Kolega M, Kunac SF. The effects of drinking water on attention. Procedia-Social and Behavioral Sciences. 2014; 159: 57783.

2. Popkin BM, D'Anci KE, Rosenberg IH. Water, hydration and health. Nutrition reviews. 2010; 68: 439-58.

3. Orrù S, Imperlini E, Nigro E, Alfieri A, Cevenini A, Polito R, et al. Role of functional beverages on sport performance and recovery. Nutrients. 2018; 10: 1470.

4. Nuccio RP, Barnes KA, Carter JM, Baker LB. Fluid Balance in Team Sport Athletes and the Effect of Hypohydration on Cognitive, Technical and Physical Performance. Sports Med. 2017; 47: 1951-82.

5. Shirreffs SM. Hydration in sport and exercise: water, sports drinks and other drinks. British Nutrition Foundation Nutrition Bulletin. 2009; 34:374-9.

6. El-Sharkawy AM, Sahota O, Lobo DN. Acute and chronic effects of hydration status on health. Nutrition Reviews. 2019; 73: 97-109.

7. McCartney D, Desbrow B, Irwin C. The effect of fluid intake following dehydration on subsequent athletic and cognitive performance: a systematic review and meta-analysis. Sports medicine-open. 2017; 3:1-23.

8. Athanasatou A, Kandyliari A, Malisova O, Kapsokefalou M. Fluctuation of water intake and of hydration indices during the day in a sample of healthy Greek adults. Nutrients. 2019; 11: 793.

9. Secher M, Ritz P. Hydration and cognitive performance. The Journal of Nutrition, Health \& Aging. 2012; 16: 325-9.

10. Holdsworth JE. The importance of human hydration: perceptions among healthcare professionals across Europe. Nutrition Bulletin. 2012; 37: 16-24.

11. Nuccio RP, Barnes KA, Carter JM, Baker LB. Fluid Balance in Team Sport Athletes and the Effect of Hypohydration on Cognitive, Technical, and Physical Performance. Sports Med. 2017; 47:1951-1982.

12. Ayotte D, Corcoran MP. Individualized hydration plans improve performance outcomes for collegiate athletes engaging in in-season training. Journal of the International Society of Sports Nutrition. 2018; 15: 27.

13. Liska DA, Mah E, Brisbois T, Barrios PL, Baker LB, Spriet LL. Narrative Review of Hydration and Selected Health Outcomes in the General Population. Nutrients. 2019; 11: 70.

14. Jequier $\mathrm{E}$, Constant $\mathrm{F}$. Water as an essential nutrient: the physiological basis of hydration. European Journal of Clinical Nutrition. 2010; 64:115-23.

15. Benelam B, Wyness L. Hydration and health:a review. Nutrition Bulletin. 2010; 35: 3-25. 